\title{
José da Cunha Brochado: de secretário de embaixada a embaixador extraordinário
}

\author{
Ana Luiza de Castro Pereira Gomes ${ }^{[1]}$
}

\begin{abstract}
Resumo
Neste artigo, serão apresentados alguns aspectos da trajetória de José da Cunha Brochado, um dos mais proeminentes indivíduos do cenário político da história de Portugal nos séculos XVII e XVIII. Iniciou seu percurso no palco das relações internacionais na qualidade de secretário de embaixada de d. Luís Álvares de Castro, segundo marquês de Cascais entre 1695-1704 em Paris. Em suas cartas e memórias, Brochado revelou não somente aspectos relacionados com a vida na corte, mas com o comportamento adotado por d. Luís Álvares de Castro. Percebe-se que a estada nas cortes europeias demandava não somente conhecimento político, mas também habilidade para circular nos mais diferentes ambientes e conviver com hábitos sociais e culturais bastante distintos, características essas que Brochado acreditava ter.
\end{abstract}

Palavras-chave: diplomacia; José da Cunha Brochado; Portugal.

\section{José da Cunha Brochado: Embassy Secretary of the Ambassador Extraordinary}

\begin{abstract}
This article points out some aspects of José da Cunha Brochado's trajectory. He was one of the most prominent individuals in the political landscape of the history of Portugal, in the seventeenth and eighteenth centuries, starting his journey on the stage of international relations as secretary of embassy of d. Luís Álvares de Castro, second marquess of Cascais, in Paris, between 1695-1704. In his letters and memories, Brochado revealed not only aspects related to the royal life but, more specifically, related to the one adopted by d. Luís Álvares de Castro's behavior. It is noticed that, being in European courts demanded not only political knowledge, but also the ability to circulate in many different environments and live with very different social and cultural habits. Brochado believed he had those characteristics.
\end{abstract} Keywords: diplomacy; José da Cunha Brochado; Portugal.

\section{José da Cunha Brochado: de secrétaire d'ambassade à ambassadeur extraordinaire}

\section{Résumé}

Cet article présente certains aspects du parcours de José da Cunha Brochado, l'une des figures les plus remarquables du panorama politique de l'histoire du Portugal des XVII ${ }^{\text {ème }}$ et XVIII ${ }^{\text {ème }}$ siècles. Il débuta sa carrière sur la scène des relations internationales en tant que secrétaire d’ambassade de d. Luís Álvares de Castro, deuxième marquis de Cascais (1695-1704) à Paris. Dans ses lettres et mémoires, Brochado rapporte des faits liés non seulement à la vie à la cour, mais également au comportement de d. Luís Álvares de Castro. On en déduit que la fréquentation des cours européennes demandait, d’une part, des connaissances politiques et, d’autre part, la capacité de circuler dans des milieux variés et de s'adapter aux diverses coutumes sociales et culturelles, des qualités que Brochado était convaincu de posséder

Mots-clés : diplomatie ; José da Cunha Brochado ; Portugal.

\section{José da Cunha Brochado: secretario de embajada a embajador extraordinario}

\section{Resumen}

En este artículo se presentan algunos aspectos de la trayectoria de José da Cunha Brochado, uno de los individuos más relevantes de la escena política portuguesa, durante los siglos XVII y XVIII. Inició su carrera, en el palco de las relaciones internacionales, en Paris, como secretario del embajador (o secretario de la embajada de) d. Luís Álvarez de Castro, 2º marqués de Cascais, entre 1695 y 1704. En sus cartas y memorias, Brochado revela aspectos no sólo relacionados con la vida en la corte, sino también con el comportamiento adoptado por d. Luís Álvares de Castro. Se constata que las estancias en las cortes europeas exigían no sólo conocimiento político, sino también habilidades para circular y convivir con hábitos sociales y culturales bastante distintos, características estas que Brochado consideraba que poseía.

Palabras-clave: diplomacia; José da Cunha Brochado; Portugal. 


\section{Introdução}

$\mathrm{N}$

os últimos anos, a história da diplomacia vem ocupando um espaço significativo nas linhas de investigação, que se dedicam não somente ao papel político que os embaixadores desempenharam ao longo dos séculos, mas também à sua participação sociocultural na difusão do saber. ${ }^{1} \mathrm{O}$ aparecimento da figura do ambasciatore, na qualidade de representante do rei como das embaixadas de caráter permanente ocorreu na Itália do século XV (Mattingly, 2003, p. 423-439; Fubini, 2000, p. 111-121) diante da necessidade de reduzir os riscos que a circulação do rei poderia causar. A monarquia espanhola foi a pioneira no envio de um representante permanente para o exterior, nomeadamente para a corte inglesa.

A necessidade de definir com maior exatidão o papel que seria desempenhado por um representante diplomático deu origem a vários tratados, entre os quais a obra De la charge et dignité de l'ambassadeur..., de Jean Hotman de Villières, que foi publicada na primeira década do século XVII. Em 1682, Abraham de Wiquefort publicou L'ambassadeur et ses fonctions, que rapidamente passou a ser obra de referência para os indivíduos inseridos na atividade diplomática. Diante da importância que o papel de ambasciatore assumiu no contexto das relações entre as nações modernas no século XVIII, François Callières publicou, em 1716, De la manière de negotier avec les souverains, que tinha como enfoque principal o papel desempenhado pelos representantes diplomáticos nas negociações. A expressão negociante foi introduzida por François Callières para nomear os representantes diplomáticos. Em sua obra, Callières analisou não somente os privilégios dos ministros estrangeiros, mas também a maneira de organização das cerimônias de entrada e saída dos embaixadores e os deveres particulares deles. Com sua publicação, De la manière de negotier avec les souverains passou a ser o manual mais consultado pelos representantes diplomáticos.

É importante ter em conta que a redação desses e de outros tratados aconteceu em meio a um contexto político conturbado na Europa. Entre 1618 e 1648, a paz no continente europeu esteve suspensa, sendo esse período conhecido como a Guerra dos Trinta Anos. A Paz de Westfália, ${ }^{2}$ também conhecida como os Tratados Münster e Osnabrück, representou o marco definidor da paz, ao serem reconhecidas, concomitantemente, as Províncias Unidas e a Confederação Suíça. Foi a primeira vez que a soberania dos Estados envolvidos foi legitimada.

\footnotetext{
Sobre o papel dos embaixadores na qualidade de difusores culturais e do conhecimento, ver Furtado (2012): Faria (2008); e Clunny (1999 e 2006).

${ }^{2}$ A Paz de Westfália, também conhecida tendo como referência os Tratados de Münster e Osnabrück (ambas cidades que, atualmente, pertencem à Alemanha), constituiu uma série de tratados que culminaram com o fim da Guerra dos Trinta Anos e o reconhecimento das Províncias Unidas. Diante da incapacidade de reunir em um mesmo local protestantes e católicos, a saída encontrada para darem início às conversações cuja paz era o objetivo final foi sediar o encontro dos protestantes na cidade de Osnabrück, enquanto os católicos reuniam-se em Münster. Portugal, nessa ocasião com o trono recém-restituído à dinastia dos Bragança, enviou para Münster o plenipotenciário Luiz Pereira de Castro, acompanhado pelos embaixadores Ruy Botelho de Moraes e Francisco de Sousa Coutinho.
} 
A entrada de Portugal no cenário das relações internacionais ocorreu em $1640,{ }^{3}$ ano em que a dinastia de Bragança buscou seu lugar no palco da diplomacia moderna. D. João IV percebeu que era urgente nomear seus embaixadores para as principais cortes da Europa moderna na época. A posição que o recém-coroado monarca ocupava na política internacional, sendo visto como rei legítimo por alguns e rebelde ${ }^{4}$ por outros, não tornou fácil a estada no estrangeiro para os primeiros embaixadores ${ }^{5}$ portugueses. A legitimação (Cardim, 2005, p. 58) de d. João IV na qualidade de rei passava, pois, pela colocação estratégia de representantes diplomáticos naquelas que eram consideradas as principais cortes europeias: para Paris, foi nomeado d. Francisco de Melo, acompanhado pelo dr. António Coelho de Carvalho, constando em suas instruções:

Que fosse necessário mostrar-se a El-Rei de França, e a seus Ministros a justificação do direito e justiça com que ele D. João havia sido restituído ao trono, se valeriam os papéis que lhes haviam sido entregues, e do mais que lhes ocorresse, com advertência porém que se deveriam escusar de o fazer e pôr em dúvida o que era tão notório e conhecido no mundo, se não houvesse disso necessidade. (Visconde de Santarém, 1843, p. 13)

A corte de Londres recebeu d. Antão Vaz de Almada como representante do monarca português, acompanhado pelo dr. Francisco de Andrade Leitão; para Haia, foi enviado Tristão de Mendonça Furtado; a Suécia recebeu Francisco de Sousa Coutinho; Copenhague recebeu, de maneira privada, Francisco de Sousa Coutinho; para a Catalunha, foi enviado o padre Inácio de Mascarenhas; e, finalmente, Roma recebeu, na qualidade de bispo de Lamego, d. Miguel de Portugal. A especificidade dessas primeiras seis embaixadas reside no perfil de cada um dos escolhidos para chefiá-las. Para três delas, por exemplo, foram escolhidos dois indivíduos, sendo um deles membro do grupo de fidalgos que liderou a restauração do trono, e o outro, um especialista em direito civil ou canônico.

Nos anos que se seguiram às primeiras embaixadas portuguesas, é possível perceber que o cuidado dos monarcas na escolha de seus representantes diplomáticos permaneceu relacionado com a importância da corte para onde eram enviados. O caráter de cada enviado era, assim, definido consoante a natureza da missão.

\footnotetext{
${ }^{3}$ As guerras e sublevações que aconteceram naquele período um pouco por toda a parte na Europa tiveram, no caso português, um desfecho distinto, culminando com a substituição da monarquia. Tal acontecimento repetiu-se apenas na Inglaterra, proporcionando, assim, uma aliança militar e diplomática com a Inglaterra de Carlos II, que esteve no centro do ideário político responsável pela assinatura do Tratado de Paz de 1668 (Valladares, 2006).

${ }^{4}$ A insurreição portuguesa assumiu tal impacto nas relações internacionais que Wicquefort Ihe dedicou um capítulo especial em L'ambassadeur et ses fonctions, o capítulo "Si les usurpateurs, et les gouverneurs en chefs peuvant envoyer des ambassadeurs" (Wicquefort, 1730)

${ }^{5}$ Francisco de Andrade Leitão, nomeado para a corte da Holanda, teve a casa pilhada e incendiada em Haia em 1642; Pantaleão de Sá e Meneses foi nomeado para a corte de Londres e executado em 1654.
} 


\section{A nomeação de um representante diplomático: caráter e importância}

A proposta deste artigo é analisar a trajetória de um dos mais proeminentes diplomatas portugueses do período moderno. Contudo, torna-se fundamental esclarecer as distinções existentes quanto ao caráter de cada função diplomática, uma vez que, como veremos adiante, será esse um critério importante na definição do papel desempenhado por Brochado em suas enviaturas. Antônio de Moraes Silva (1789a, p. 144) definiu caráter como sendo "o estilo de qualquer pessoa, os atributos, qualidades, propriedades, hábitos, propensões, costumes, gênio que distinguem e caracterizam o sujeito". No cenário da diplomacia, o caráter de um representante diplomático, seja de embaixador ordinário, residente, embaixador extraordinário ou ministro plenipotenciário, era definido consoante sua missão no exterior.

\section{A entrada de Portugal no cenário das relações \\ internacionais ocorreu em 1640, ano em que a \\ dinastia de Bragança buscou seu lugar no palco da diplomacia moderna}

É importante consideramos a própria consolidação da ideia de diplomacia e de seu léxico naquele período. Aqueles que estudam ou se interessam pelo mundo da diplomacia veem recorrentemente o uso dos seguintes conceitos: negociação, representação, etiqueta, cerimonial, protocolo, precedência, entre outros. Todos são importantes para compreender o cotidiano que cercou e cerca os representantes diplomáticos quando destacados para missões no estrangeiro.

A ideia que predomina nos tratados e estudos sobre a diplomacia moderna, tendo como exemplo a obra publicada por Wicquefort em 1676, é a de que o embaixador, na qualidade de representante de seu monarca, deveria ser uma figura fiel a este, sendo sua competência para o exercício da função comprovada com experiências anteriores. Ciente disso, a escolha de um representante diplomático para uma missão no estrangeiro era sempre acompanhada da produção de um documento intitulado "instrução". Tal documento definia os objetivos e as obrigações do representante diplomático.

Segundo Pedro Cardim, a instrução era “[...] um documento que, no fundo, era uma espécie de compromisso de prestação de serviços e que criava, antes de mais, obrigações com caráter jurídico". (Cardim, 2002, p.71) Somado a isso, o embaixador deveria ter pleno conhecimento dos assuntos para os quais era indicado. Um ministro estrangeiro do rei deveria ter três qualidades: nascimento, estudo e experiência. No que tocava à primeira, o nascimento, Wicquerfort entendia como “[...] l'excellence du naturel, et la force du génie".(Wicquerfort, 1730, p. 
83) Já Francisco Rodrigues Lobo, na obra Corte na aldeia, publicada em 1619 e considerada por muitos estudiosos a primeira obra da literatura barroca de Portugal, advertia que era preciso grande cuidado na escolha do embaixador:

[...] devem ser escolhidos para este cargo de Embaixador os homens das famílias mais ilustres do Reino, dos ilustres os mais discretos e cortesãos, destes os mais animosos e liberais, dos animosos os mais apessoados, e de todos os mais bem acostumados. (Lobo, 1890, p. 81)

Quanto ao caráter atribuído a um embaixador no estrangeiro, variava consoante as missões para as quais ele era destacado; ou seja, um embaixador extraordinário (Bluteau, 1728a, p. 41) era nomeado para "[...] a corte de algum Príncipe, para tratar de algum negócio particular, como a conclusão de um matrimônio, a condução de uma Rainha, congratulações pelo aniversário ou pêsames pelo falecimento de um membro da família real"; já um embaixador ordinário caracterizava-se como aquele que, "[...] com a continuação da sua assistência, cultiva a recíproca amizade de um Príncipe com outro, e maneja os negócios que sobrevêm” (Bluteau, 1728a, p. 41); Residente era “[...] aquele ministro que faz os negócios de uma República, ou de um Príncipe pequeno, na corte de um Rei" (Bluteau, 1728c, p. 282); ministro plenipotenciário era aquele “[...] que tem do seu Rei, todo o poder necessário para a negociação de uma paz, um casamento"; 6 enviado, segundo Bluteau, era um ministro político mandado pelo monarca a outra corte para tratar de algum negócio. ${ }^{7}$ Nota-se que a escolha de um embaixador era das tarefas mais importantes e que requeria grande cuidado por parte do monarca.

O envio de uma missão diplomática para uma corte europeia no período moderno era um momento de grande importância para a monarquia e estava cercado de todo um aparato político, financeiro e social. Ao monarca cabia a nomeação cuidadosa daquele que seria seu representante no exterior. No rol dos criados, o secretário da embaixada era aquele cujo perfil distinguia-se dos demais e que assumia, no cotidiano dos embaixadores e das embaixadas, um papel fundamental por ser responsável pela produção, organização e despacho da documentação criada pela embaixada.. A documentação produzida para e pelas embaixadas passava pelas mãos dos secretários, razão pela qual a escolha era feita diretamente pelo rei. José da Cunha Brochado foi um dos que figuraram inicialmente, no cenário da diplomacia, na qualidade de secretário da embaixada em 1695, tendo registrado em suas memórias o que, naquela altura, se esperava dos membros das famílias dos embaixadores: “[...] que sejam bem educados, de boa vida, e presença, assim por se livrar de acidentes danosos" (Brochado, 1996, p. 40). E, mais adiante, admite que o comportamento de

${ }^{6}$ Bluteau (1728b, p. 548). Já Antônio de Moraes Silva, em 1789, definiu plenipotenciário como um ministro que tem plenipotência, ou seja, plenos poderes concedidos pelos soberanos para tratar negócios políticos com outro monarca (Silva, 1789b, p. 459).

${ }^{7}$ Morais Silva caracteriza o enviado como um ministro com graduação inferior à de embaixador que era enviado para outra corte estrangeira. 
um criado "[...] não se trata, e critica como pessoal o seu vício, e defeito, mas compreende e envolve a toda a nação" (Brochado, 1996, p. 40).

O comentário de Cunha Brochado deixa transparecer, entretanto, certa mescla entre o caráter simbólico da representação assumida pelos membros da família do embaixador e a representação política no Estado. Na ausência do embaixador, o secretário da embaixada poderia assumir funções interinamente. Já o secretário do embaixador geralmente era um indivíduo de confiança deste, sendo sua responsabilidade a organização de toda a documentação de natureza privada produzida pelo embaixador, assim como como o seu despacho. . É interessante observar que, em alguns casos, os secretários das embaixadas percorreram mais de uma corte europeia exercendo a mesma função.

\section{De estudante de direito cível a enviado extraordinário à corte parisiense}

José da Cunha Brochado foi um dos indivíduos mais proeminentes de Portugal dos séculos XVII e XVIII em razão não somente do desempenho de funções no âmbito da diplomacia, mas do legado que deixou nos campos da memória e história do reino a que serviu. Foi membro fundador e presidente da Academia Real da História Portuguesa. ${ }^{8}$ Nasceu em 2 de abril de 1651, em Cascais, filho de Antônio da Cunha da Fonseca (governador do Castelo de São Jorge) e de Joana do Quental.

Em 1668, matriculou-se na Universidade de Coimbra, onde estudou direito cível e cânones. Tinha, à época, 16 anos de idade. A obtenção do diploma de bacharel ocorreu em 1672, e o grau de doutor em direito da Universidade de Coimbra foi-lhe atribuído um ano depois, em 1673. Contudo, no século XVII, o título de doutor em direito não garantia a entrada no mundo da judicatura. Antes de iniciar sua carreira, José da Cunha Brochado teve de se submeter à leitura de bacharéis e a uma averiguação que o Desembargo do Paço fazia sobre a vida do candidato por meio de inquirições de Genere Vita et Moribus. Nesse processo, eram convocadas sete testemunhas para atestarem seu comportamento. Após aprovação, Brochado foi nomeado pelo príncipe regente d. Pedro para o cargo de juiz de fora nas vilas de Sesimbra e Barreiro; tinha então 22 anos.

Mas a proeminente carreira de Brochado foi interrompida quando, na qualidade de juiz do Cível na cidade de Lisboa, foi sentenciado a dois anos de prisão por causa de um episódio infeliz com Bento Marques. Em linhas gerais, Roque Martins apresentou a Brochado um precatório para que Bento Marques apresentasse junto ao juiz dos Órfãos da Vila Sintra uma menor que violentamente detinha, sob pena de ser preso. Brochado deu seguimento ao precatório na qualidade de juiz executor. Concomitantemente, Bento Marques solicitou a

${ }^{8}$ A Academia Real da História Portuguesa foi fundada em 1720 por d. João V. A José da Cunha Brochado coube o assento no 35 dos 50 disponíveis, tendo recebido a missão de recolher elementos que compusessem a história da diplomacia de Portugal (Brochado, 1996, p. IX-X). 
Antônio Leitão, também juiz, que emitisse um contramandado que anulasse o primeiro. Do confronto entre as duas ordens judiciais o precatório emitido por Brochado foi interpretado como um ato de fraude, de incompetência, acarretando sua detenção.

\section{João IV percebeu que era urgente nomear seus embaixadores para as principais cortes da Europa moderna na época}

A consequência de sua prisão foi a perda do lugar de juiz do Cível de Lisboa e de todos os direitos e privilégios adquiridos com o tempo de serviço. Somente em 1682 Brochado retomou sua carreira, sendo nomeado por d. Pedro II para procurador da Câmara de Miranda, função que exerceu até 1687, quando foi nomeado para o cargo de corregedor da Casa do Cível. Na ocasião, d. Pedro II $^{9}$ justificou sua nomeação em razão de seu desempenho em todas as funções para as quais tinha sido nomeado. Em 1695, Brochado foi nomeado para a função de secretário da embaixada de d. Luís Álvaro de Castro, marquês de Cascais, em Paris. ${ }^{10}$

Apesar de Brochado ser o protagonista deste artigo, ao analisarmos sua trajetória no mundo da diplomacia é impossível não mencionar sua primeira experiência na qualidade de secretário da embaixada, assim como suas observações sobre o desempenho do embaixador d. Luís Álvaro de Castro e sobre a corte francesa. Enquanto esteve à frente da embaixada, o marquês de Cascais protagonizou episódios que, na opinião do secretário da embaixada, estavam em desacordo com o que era esperado de um representante do rei. Em uma de suas notas, Brochado diz: "O Senhor Embaixador anda logrando grandes aclamações e vivas e são os frutos que colhe dos grandes gastos que tem feito, veremos se depois se correspondem as comendas a estes serviços em que tanto se acredita a nobreza de Portugal, e se interessa a nossa Pátria." ${ }^{11}$

Em relação à corte de Paris, Brochado afirmou em uma de suas notas que

El-Rey de França entre os muitos meios que tem buscado para incitar os seus vassalos ao estudo das Artes e Sciencias com que tanto enobrece o seu Reino, tem ordenado que se dêm ao seu Chanceler 18.000 libras cada ano para repartir pelos sogeitos que mais se aplicassem ao estudo, e mais trabalhassem em proveito público. ${ }^{12}$

\footnotetext{
${ }^{9} \mathrm{Na}$ cultura política do século XVII, o desempenho de serviços prestados ao rei estava relacionado diretamente com a expectativa de retribuição. Nesse contexto, não foram somente os embaixadores que usaram seu próprio espólio para sua manutenção nas cortes estrangeiras. Os mais altos servidores do rei, nas mais diversas esferas, utilizaram suas fortunas pessoais imbuídos da ideia de que, posteriormente, seriam recompensados. Sobre a economia de favores no Antigo Regime, ver Xavier e Hespanha (1993, p. 381-393). 10 Sobre as relações bilaterais entre Portugal e França pós-Restauração, ver Velho (1895-1896) e Amzalak (1943).

${ }^{11}$ Arquivo Nacional da Torre do Tombo (ANTT). Coleção de São Vicente, livro 25, carta de 22 de abril de 1696, fl. 12 ${ }^{12}$ Biblioteca Nacional de Portugal (BNP). Fundo Geral, cód. 4438, fl. 38.
} 
A sociedade francesa foi o foco de algumas outras observações de Brochado, que ressaltou, em sua maioria, o aspecto da aparência que prevalecia naquela corte. Diz ele: “[...] mas nesta corte como o exterior seja dourado, pouco importa que o interior esteja cheio de lágrimas e gemidos". ${ }^{13}$

Enquanto ocupou a função de secretário da embaixada, um de seus objetivos foi “[...] mostrar aos meus naturais que não vim a França ver só óperas e comédias e a entorpercer-me toda a vida na simples gramática de hum secretaria". ${ }^{14}$

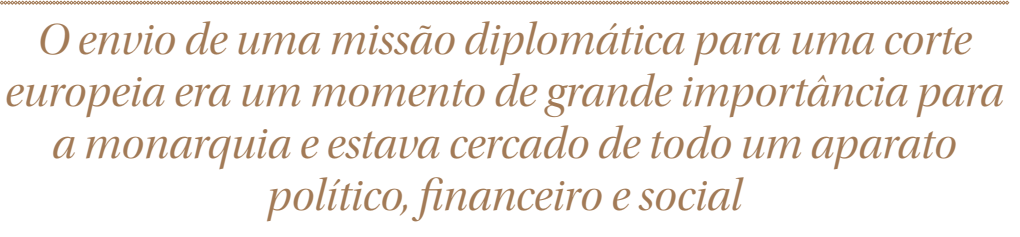

A nomeação para secretário da embaixada não foi aceita por Brochado com bons olhos, e sua experiência na corte parisiense acabou por habilitá-lo para que sua carreira no palco da diplomacia assumisse outro contorno. "Bem sey que todos hão-de julgar que perdi o juízo ou que tenho muito mau gosto, porque viver em Paris a custa d'El-Rey, em casa de hum Embaixador que me honra muito, he huma fellicydade tão completa." Sua pretensão era, sim, a nomeação para embaixador, função que nunca viria a ocupar, pois na hierarquia do mundo da diplomacia um secretário de embaixada jamais assumiria mais que a função de enviado.

Na qualidade de secretário da embaixada, membro da família do embaixador d. Luís Álvares de Castro, Brochado enfatiza que, em conformidade com as regras que faziam parte da corte francesa:

O maior acerto é levar poucos criados, mas muito bem concertados; [...] porque ter muitos sem estas assistências é destruir o crédito com uns testemunhos perpétuos, como nos sucedeu entrando em Paris com vinte pessoas cobertas de parrilha da nossa terra. (Brochado, 1996, p. 40)

Contudo, a relação de Brochado com o embaixador tinha momentos de rispidez. Tanto nas cartas quanto nas memórias são recorrentes as queixas do secretário sobre seu superior. Brochado chegou a afirmar que:

É tão necessária a modéstia de um Embaixador, e deve ele usar com tanta atenção das liberdades do país em que não nasceu, entendendo, que lhe custe alguma macha na opinião, principalmente em uma corte, aonde se não perdoa nada, que porque o Marquês de Cascais D. Álvaro em França teve algum excesso d'este uso da liberdade da corte, não valei toda a sua

\footnotetext{
${ }^{13}$ Carta a um desconhecido, de 13 de julho de 1698 apud Dória (1944, p. 42).

${ }^{14}$ Carta a um desconhecido, de 19 de outubro de 1698 apud Dória (1944, p. 60).
} 
magnificência e boas virtudes para escusar a censura, que dele se fez no libro da vida de D. Antônio. É necessário entender um estrangeiro, que lhe não é lícita toda a liberdade do país. (Brochado, 1996, p. 31)

Estar na corte do Rei Sol, cujas normas comportamentais eram das mais rígidas, exigia bastante responsabilidade, tanto dos ministros estrangeiros quanto de seus familiares. Na sociedade de corte de Norbert Elias (1974), as regras de etiqueta presentes na corte francesa e que acabaram por ser adotadas em outras cortes europeias, como a portuguesa, caracterizaram-se como uma maneira de controle da nobreza francesa e de todos aqueles que pela corte circulavam. Os efeitos da quebra de protocolos importantes nessa sociedade de corte podiam ser desastrosos, ${ }^{15}$ como relatou Brochado a respeito do comportamento de seu superior, o marquês de Cascais, que por vezes poderia ser danoso para a imagem de Portugal e de seu rei.

Temo muito que enganem aos nossos Ministros, e que cuidem, que se não jogarem na corte de França farão pequena figura, e procederá isto de que o Marquês de Cascais tem sido até extremosamente venturoso de tal maneira, que nuca fez perda. [...] e como jogou sempre, e entrou nas maiores e menores partidas do jogo, é provável, que para cobrir esta demasiada inclinação persuada, que o jogo é útil e necessário ao ministério.

Conhecedor do protocolo que envolvia o cotidiano de um embaixador no exterior, Brochado, em uma de suas memórias, à medida que narra a entrada de seu superior na corte de Luís XIV, apresenta, pormenorizadamente, o que se esperava naquela altura de um embaixador nas visitas à corte. Disse ele:

Quando o Marquês de Cascais, depois da sua audiência pública, buscou no mês de março de 96 a El-Rei Jacques no Palácio de S. Germain, que é quatro léguas de Paris, levou todo o estado, que se compunha de carroças da sua entrada com estribeiro, e pajens a cavalo. Entrou no pátio, e chegando o seu coche à porta principal da escada e quatro d'El-Rei lhe foi dito, que ele estava indisposto. [...] Porém a razão principal, que havia para não ir ver em cerimônia El-Rei Jacques, era por ser indigno que S. Majestade reconhecesse no mesmo tempo por seus Ministros dois reis de Inglaterra. (Brochado, 1996, p. 41)

\footnotetext{
${ }^{15}$ Na história das relações internacionais entre Portugal e França, um dos episódios diplomáticos desastrosos foi responsável pela interrupção das relações por cerca de 15 anos. Em 1724, chegou a Lisboa o abade de Livry na condição de embaixador francês. Diogo Mendonça de Corte Real era o secretário de Estado. O cerimonial para recebimento do embaixador francês estava sendo preparado quando os responsáveis pelo protocolo se depararam com uma diferença protocolar da corte francesa: o abade de Livry, antes de remeter ao rei sua Carta Credencial, alegou que a "maneira correta" de se proceder era que o secretário de Estado fosse primeiramente visitá-lo. Já Diogo de Mendonça recusou-se a cumprimentá-lo primeiro, justificando também não ser essa a forma protocolar correta. As diferenças entre o embaixador francês e o secretário de Estado português estenderam-se por mais de três meses, sem que nenhum dos lados cedesse. O resultado foi a interrupção das relações entre Portugal e França por 15 anos, como dito.
} 
Em suas memórias, Brochado registrou o quão era conhecedor do protocolo diplomático. Em Lição a embaixadores, descreveu o comportamento esperado de um embaixador, devendo assegurar-se que em sua família fossem bem-educados e "[...] de boa presença, assim por se livrar de acidentes danosos, como por não malquistar a sua nação com o mau procedimento, e mau ensino dos seus criados" (Brochado, 1996, p. 40). E acrescenta dizendo que, "[...] quando um português obra mal, dizem todos - este homem é mal procedido, e quando um do séquito do Embaixador procede como não convém, dizem logo - estes portugueses são malcriados". O próprio marquês de Cascais, enquanto esteve à frente da embaixada em Paris, passou por situações desfavoráveis com seus criados. Um dos episódios foi protagonizado por um deles e pelos lacaios de Monsieur de Barbieux, secretário de Guerra francês. À chegada da Ópera em Paris, o criado português e os lacaios franceses não chegaram a um acordo sobre a prioridade na entrada das carruagens de seus senhores. Tal desentendimento culminou com a agressão a um dos criados do embaixador português, que, em retaliação, mandou sovar os lacaios de Monsieur de Barbieux. ${ }^{16}$ Os problemas protocolares criados e enfrentados pelo marquês de Cascais não pararam por aí. Ao longo de suas cartas e memórias, Brochado relatou vários, e muitas vezes o fazia com o objetivo de mostrar a incapacidade de seu superior na representação de seu monarca.

Brochado era um homem ambicioso, e a notícia de que a embaixada em Paris ficaria vaga com a saída do marquês de Cascais fez com que o então secretário registrasse em suas memórias o desejo de assumir aquela função, antes de retornar para Portugal dizendo: “[...] para voltar com mais autoridade para a minha terra e empregar em utilidade dela o fruto das minhas vigílias. [... ] mais para evitar a nota de exclusão que para conseguir a honra do ministério". ${ }^{17} \mathrm{E}$ foi mais longe nas manifestações que fez sobre a ocupação daquela função na corte parisiense ao enviar uma carta para o então secretário de Estado de d. Pedro II, Mendo de Fóios Pereira, dizendo:

Tomara ao menos que nesta ocasião nomeassem um tal Enviado ou um tal Ministro que pela sua grande pessoa, talento e serviço me fizesse glória a disputa e vantagem a competência, porque, como dizia um discreto, havendo de ser devorado antes o quero ser de um leão que de um rato. ${ }^{18}$

Em outra carta enviada ao secretário de Estado Mendo de Fóios Pereira, Brochado expressou suas expectativas no tocante ao comportamento de um bom embaixador. Ao que tudo indica, sua intenção era demonstrar seu conhecimento acerca das qualidades esperadas de um representante do rei. Disse ele em uma das cartas que:

${ }^{16}$ Sobre o caso de Monsieur de Barbieux, ver O caso de Barbiseux apud Brochado (1996, p. 35).

${ }^{17}$ Carta a um desconhecido, de 19 de outubro de 1698 apud Dória (1944, p. 59).

${ }^{18}$ Carta a um desconhecido, de 28 de junho de 1699 apud Dória (1944, p. 93). 
[...] quanto o embaixador é mais grande senhor, tanto é maior o cuidado da sua magnificência, da sua casa, das suas equipagens, das suas entradas e das suas cerimônias, que lhes leva todo o tempo, e esta é uma das razões por que as cortes estrangeiras se não servem de grandes senhores para embaixadores. ${ }^{19}$

O estatuto de Brochado foi alterado quando, em 1698, foi nomeado enviado extraordinário para a corte de Paris, função que ocupou até 1704. Sobre sua nomeação, afirmou:

[...] nesta posta tive aviso particular do Secretário de Estado de que El-Rei me tinha nomeado para seu Enviado nesta corte. Suponho que já nessa será público esta notícia, que estimo pela parte da honra e que procurei com os olhos nos interesses temporais $\left[\ldots . . .{ }^{20}\right.$

Uma vez na qualidade de enviado extraordinário na corte parisiense, suas correspondências mudaram sensivelmente de tom. Se, na qualidade de secretário da embaixada, Brochado tinha o olhar voltado para o desempenho de seu superior e para os aspectos relacionados com a aparência, tão evidentes na corte francesa, na qualidade de enviado interessava-lhe muito mais os aspectos da política internacional.

Sua trajetória assemelha-se à de Duarte Ribeiro de Macedo (1618-1680), ${ }^{21}$ Diogo de Mendonça Corte Real (1658-1736), d. Luís da Cunha (1662-1749)22 e

\footnotetext{
${ }^{19}$ Carta a um desconhecido, de 19 de outubro de 1698 apud Dória (1944, p. 73).

${ }^{20}$ Carta a Mendo de Fóios Pereira, de 14 de junho de 1699 apud Dória (1944, p. 88).

${ }^{21}$ Diplomata e jurisconsulto do século XVII, Duarte Ribeiro de Macedo figurou entre os mais importantes pensadores da ciência política daquele século. Nasceu em 1618, filho de um magistrado e de uma descendente de artesãos, e estudou direito na Universidade de Coimbra. Entre as funções desempenhadas, foi desembargador da Casa Real e membro do Conselho da Fazenda. Sua "carreira" na diplomacia teve início em 1659, quando ocupou a função de secretário da embaixada de d. João da Costa, o conde de Soure, na França. Depois disso, foi designado para enviado ordinário em Paris (1668-1676) e enviado extraordinário em Madri (1677-1679). De sua atuação no cenário da diplomacia ficaram obras como Discurso político que o conde de Soure [...] deu ao cardeal Mazarine [...]. Mostra-se por 27 razões forçosíssimas, como França por justiça, e por conveniência não devia fazer a paz sem inclusão de Portugal e Juízo histórico, jurídico, politico sobre a paz celebrada entre as Coroas de França e Castela no ano de 1660. Postumamente, foram publicados Discursos políticos e obras métricas de Duarte Ribeiro de Macedo, olissiponense, desembargador dos Agravos, do Conselho de S. Magestade, \& do de sua Fazenda, enviado ordinário à Corte de França, \& extraordinário à de Castela, \& Turim, Cavaleiro da Ordem de Cristo, \& etc.; Obras do doutor Duarte Ribeiro de Macedo, Cavaleiro da Ordem de Cristo...; Cartas do padre Antônio Vieira da Companhia de Jesus a Duarte Ribeiro de Macedo. A publicação mais recente sobre o percurso político de Duarte Ribeiro de Macedo é a obra de Faria (2005)

22 Diplomata do período joanino, d. Luís da Cunha nasceu em 1662 e formou-se em cânones na Universidade de Coimbra em 1686, sendo logo nomeado desembargador da Relação no Porto e, posteriormente, em Lisboa. Em 1696, foi nomeado embaixador de Portugal em Londres e, posteriormente, enviado extraordinário das cortes de Madri e Paris e ministro plenipotenciário no Congresso de Utrecht. Foi, também, um dos grandes pensadores políticos portugueses do século XVIII. Entre as obras publicadas por Cunha estão: Testamento político de dom Luís da Cunha, 17-; Ideia da guerra de 1702, com verdadeira, e exata notícia das potências, e convenções dos príncipes da Europa e dos mais sucessos na mesma acontecidos desde o anno de 1659 até o de 1706... / que ao senhor d. João 5o... offerece Dom Luis da Cunha... 1714; Memorias da paz de Utrecht offerecidas a el-rey n.s. por d. Luís da Cunha, seu embaixador extraordinario e plenipotenciario no congresso da dita paz quarta e ultima parte [manuscrito]: quarta parte: memorias do que se passou no congresso de Utrecht até que totalmente se terminou com a paz concluída entre Portugal e Castella, 1715; entre outras. Sobre a trajetória política de d. Luís da Cunha, ver Silva (2008-2009), Clunny (1999) e Silva (2003).
} 
Alexandre de Gusmão (1695-1753), ${ }^{23}$ homens que Jaime Cortesão designou de "estrangeirados". ${ }^{24}$ Nesse sentido, a maneira muitas vezes inflamada com que descreveu a corte parisiense levou-o a afirmar em uma de suas cartas a um destinatário desconhecido: "Pouca razão tem V. M. de me supor francês naquele discurso, porque lhe afirmo que nada amo menos que esta nação. Conheço as inconstâncias do seu gênio, as impiedades da sua política e as extravagâncias da sua altiveza." 25

\section{Na ausência do embaixador, o secretário da embaixada poderia assumir funções interinamente}

A erudição de Brochado pode ser percebida ao longo de todas as correspondências que trocou não somente com outros diplomatas, mas também com amigos e familiares. Aspectos da política nacional e internacional, da sociedade e cultura, entre outros, são analisados por ele de maneira singular. Chegou a ser classificado por Antônio Álvaro Dória, autor do prefácio das cartas de Brochado, como "[...] um dos poucos portugueses europeus do século XVIII” (Dória, 1944, p. XII-XIV). Em uma carta de 1698, cujo destinatário desconhece-se, Brochado teceu alguns comentários sobre a questão da educação em Portugal, dizendo:

Confesso tudo o que V. M. me escreve sobre o excelente gênio dos nossos compatriotas, mas torno a dizer a V. M. Que, enquanto não houver educação, não há-de haver homens. Desta grande arte depende a sua segunda formação ou segunda natureza. A primeira nos distingue mal do resto dos animais; esta nos faz superior $[s i c]$ a eles. Uma nos formou homens, outra, falando como filósofo, nos iguala aos deuses. Se educação, a razão mal atina com o homem, e com ela o instinto rende a sua homenagem à razão. ${ }^{26}$

\footnotetext{
${ }^{23}$ Alexandre de Gusmão nasceu no Brasil em 1695, mas em 1710 mudou-se para Lisboa, tendo sido, quatro anos mais tarde, escolhido como secretário da embaixada de Portugal em Paris, onde acabou por cursar direito civil na Universidade de Sorbonne. A estada em Paris permitiu-lhe conhecer não somente a história política e a legislação de muitas nações europeias, como também personalidades que transitavam no palco da diplomacia. Uma vez de volta a Portugal, em 1719, os vastos conhecimentos sobre a política internacional Ihe renderam frutos, e ele acabou sendo enviado para Roma, onde assumiu a função de embaixador de Portugal junto à Santa Sé até 1728. Entre os anos 1746 e 1750, dedicou-se à negociação do Tratado de Madri, que estabeleceu as fronteiras entre as colônias portuguesas e espanholas na América do Sul. Sobre a trajetória de Alexandre de Gusmão, ver Cortesão (1950).

${ }^{24}$ Denominam-se estrangeirados, na história de Portugal, os intelectuais portugueses que, em finais do século XVII e, sobretudo, no século XVIII, depois do contato com a revolução científica e a filosofia das Luzes, retornaram para Portugal. Entre os estrangeirados estavam: Alexandre de Gusmão, Francisco Xavier de Oliveira, d. Luís da Cunha e Sebastião José de Carvalho e Mello.

${ }^{25}$ Carta a um desconhecido, de 29 de junho de 1698 apud Dória (1944, p. 38).

${ }^{26}$ Carta a um desconhecido, de 7 de agosto de 1698 apud Dória (1944, p. 51-52).
} 
A nomeação para secretário marcou o início de sua "carreira" no palco da diplomacia portuguesa do Antigo Regime. Posteriormente, assumiu a função de enviado extraordinário nas cortes de Paris, Londres e Madri. O caráter de enviado era o posto máximo que Brochado poderia assumir no palco da diplomacia portuguesa, uma vez que não pertencia à grande nobreza (Monteiro, 2003, p. 370).

José da Cunha Brochado esteve à frente da embaixada de Portugal na França por nove anos. Ao longo desse período, produziu um vasto rol de notícias sobre a corte parisiense. Apesar de em uma de suas cartas ter registrado: "Não obrei, pois, ação que mereça ser escrita, nem escrevi relação ou fiz discursos que mereçam ser lidos", sua produção literária (Brochado, 1761), não só no campo da diplomacia, fez dele um dos portugueses mais importantes dos séculos XVII e XVIII. Grande parte de seus escritos encontra-se ainda inédita e dispersa nas Coleções dos Documentos e Memórias da Academia Real de História.

Contudo, a permanência de Brochado em Paris viria a se tornar complicada com o falecimento do rei Carlos II da Espanha, sucedido por Philippe d'Anjou, neto de Luís XIV. Com a coroação de Filipe V em Madri, o panorama europeu alterou-se, com França e Espanha do mesmo lado e em contraposição às coroas inglesa e holandesa. Diante desse novo quadro, Portugal, por algum tempo, optou por uma posição de neutralidade combatida, e em uma das correspondências Brochado afirmou: “[...] necessitamos de nos unir a Inglaterra e Holanda: este é o ponto de toda a dificuldade, em que não é fácil ver claro, nem distinguir a cura da enfermidade". ${ }^{27}$ Em 1701, pouco tempo depois desse pronunciamento do enviado português na França, foi assinado um Tratado ${ }^{28}$ de Amizade entre a coroa portuguesa e a francesa.

Mas a paz na Península Ibérica não durou muito tempo. Insatisfeitos com o acordo feito entre Portugal e França, a coroa inglesa acabou articulando um tratado que colocaria Portugal novamente a seu lado e acabaria por indispor espanhóis e portugueses. Nesse novo panorama, França e Espanha assumiram posição contrária à de Portugal, culminando com a declaração de guerra contra Portugal feita por Filipe V em 30 de abril de 1704. Nesse contexto, a permanência de José da Cunha Brochado em Paris tornou-se insustentável, levando

${ }^{27}$ Carta a um desconhecido, de 19 de outubro de 1698 apud Dória (1944, p. 55).

${ }^{28}$ O Tratado de Lisboa, de 18 de junho de 1701, foi firmado por Manuel Telles de Silva, Francisco de Távora e Mendo de Fóios Pereira em nome do rei Pedro II e do embaixador francês em Portugal Pierre Rouillé de Marbeuf, em representação de Felipe $V$ de Espanha, segundo os seguintes termos: reconhecimento de Felipe $V$ como rei de Espanha e encerramento dos portos portugueses aos navios de países contrários a essa sucessão; a coroa espanhola deveria indenizar Portugal pelas perdas sofridas no assento de negros nas Indias; em caso de guerra e de escassez em Portugal, a Espanha levantaria a proibição de vender pão aos portugueses; ambas as partes se comprometiam a combater o contrabando de tabaco; Espanha apoiaria Portugal, por via diplomática, no caso de guerra pela força militar, nas possíveis reclamações que Inglaterra ou as Províncias Unidas pudessem fazer pelo apoio português aos navios franceses durante a Guerra dos Nove Anos, nos conflitos territoriais que pudessem ter com esses países na Índia, Brasil, costa da Africa; se o rei da Inglaterra Guilherme III negasse a manutenção à rainha da Grã-Bretanha Catarina de Bragança, infanta portuguesa viúva de Carlos II da Inglaterra, a pensão desta se pagaria em três partes entre Espanha, Portugal e França; a Espanha cederia a Portugal a Colônia do Sacramento, revogando o acordo hispano-português de 1681; em caso de guerra, nenhum dos firmantes faria tréguas sem o consentimento do outro. O tratado teria validade por 20 anos. 
o enviado português a manifestar sua preocupação em uma carta a um desconhecido em 16 de julho de 1702:

A nossa liga com esta corte e a de Espanha, e a sua retração, não foi um acidente de pouco embaraço, e, finalmente, esta nova liga, assistindo eu ainda nesta terra, com o novo rei Carlos II em Lisboa e Filipe $\mathrm{V}$ dentro da província da Beira, foi um acontecimento da primeira exceção, que não se acha nas regras da comum política. Nem eu sei que alguns Ministros nossos, desde a primeira fundação do reino, representasse em quatro ou cinco anos de ministério tão novas e tão diferentes figuras em negociações contrárias, cheias todas de consequências da última ruína de Portugal. ${ }^{29}$

Ainda em 1702 e sobre os efeitos da aliança feita entre Portugal, Inglaterra e Holanda, Brochado escreveu:

Meu Senhor:

Vai-se acabando a minha assistência nesta corte pela nova liga que contraímos com Inglaterra, Holanda e Império. Prospere as intenções de El-Rei Nosso Senhor, para que firmemos os nossos interesses e seguremos o nosso repouso. Eu padeci vários contratempos neste ministério. [...] Enfim, saio com honra e sem desagrado de El-Rei Cristianíssimo, que me recebeu na audiência de despedida com expressões que acreditavam a boa inteligência que conservei entre as duas coroas e honesta conduta com que me comportei em todo o tempo que assisti na sua corte, e assim o mandou escrever na sua carta recredencial. [...] Eu me contento com haver servido nem bem, nem mal. Obrei mediocremente nos negócios de que fui encarregado, escrevi, com a mesma mediania, as relações dos sucessos desta corte, que se costumam referir nas cartas que chamam de ofício. [...] Não obrei, pois, ação que mereça ser escrita, nem escrevi relação ou fiz discursos que mereçam ser lidos, que é, como diz o discreto Plínio, a última desgraça de um vivente, por não deixar depois da sua morte algum sinal de haver vivido. Meu senhor, estas reflexões sombrias são efeitos do estado em que me acho, começando uma longa penível jornada. Deus me leve a salvamento e guarde a V. Ex ${ }^{\mathrm{a}}$ muitos anos. ${ }^{30}$

Percebe-se que, apesar da insustentabilidade da permanência de Brochado em Paris, não houve impedimento para que ele fosse recebido pelo rei Luís XIV. Em sua última audiência com Luís XIV, Brochado não deixou de manifestar o pesar com que deixava a corte parisiense em um discurso proferido em francês e cujo conteúdo foi o seguinte:

${ }^{29}$ Carta a um desconhecido, de 19 de outubro de 1698 apud Dória (1944, p. 160).

${ }^{30}$ Carta a um desconhecido, de 16 de julho de 1702 apud Dória (1944, p. 146-149). 
Senhor:

Não sem um extremo pesar meu, tenho hoje a honra de tomar de V. Mag.e. as terríveis desgraças do tempo presente, com que parece que quer Deus punir a Europa, me separam com violência da corte de V. Mag.e e interrompem o meu ministério. Como o entendimento do homem não toma sempre o partido do seu coração, posso ousadamente dar-me a honra de segurar a V. Majestade que El-Rey meu amo, apesar desta mesma fatal conjuntura, de que é levado impetuosamente, conserva sempre em seu Coração, os mesmos sentimentos de alta estima, e de consideração particularíssima, que ele fez conhecer em toda a ocasião pela sagrada pessoa de V. Mag.e e que não há nada no Mundo que sua Mag.e Portuguesa prefira à honra desta amizade e à paixão que a ela o leva. Quanto a mim, Senhor, tendo a honra de haver feito uma longa residência nesta corte, me farei uma obrigação, compelido da minha Consciência, a publicar em toda a parte, como testemunha irreprovável, a justiça de V. Mag.e, a sua equidade e sinceridade das suas ações, e tantas outras virtudes resplandecentes verdadeiramente reais e verdadeiramente augustas, e superiores à capacidade comum do homem, que representam a V. Mag.e o maior Monarca do Universo e, o que se deve estimar sobre tudo, um Príncipe Cristianíssimo, com título dobrado. ${ }^{31}$

Finda a permanência de Brochado em Paris, ele se dirigiu primeiramente para Haia, depois para Londres, para somente em junho de 1705 desembarcar em Lisboa. Os altos custos de vida na corte parisiense fizeram com que voltasse para Portugal bastante endividado. A recompensa por seus préstimos na corte do Rei Sol chegou um pouco tardiamente. Somente em dezembro de 1705 foi nomeado conselheiro da Fazenda. Três anos depois, foi nomeado conselheiro da rainha d. Maria Ana de Áustria, e, em 1709, desembargador do Paço. Seu bom desempenho na corte parisiense foi, posteriormente, recompensado com sua nomeação para a corte de Londres para substituir d. Luís da Cunha, onde permaneceu entre os anos 1710 e 1714. Foi ainda nomeado enviado em Madri entre 1725 e 1729. De volta a Portugal, dedicou os últimos anos de vida à Academia Real de História, falecendo em 1733.

José da Cunha Brochado, assim como d. Luís da Cunha, João Gomes da Silva (conde de Tarouca), Sebastião José de Melo e Carvalho (marquês de Pombal) e Duarte Ribeiro de Macedo, foram atores importantes no cenário da política internacional portuguesa dos séculos XVII e XVIII. Mas, desses indivíduos que citamos, somente dois deles trilharam caminhos semelhantes no tocante à "carreira" diplomática: Duarte Ribeiro de Macedo e José da Cunha Brochado, que de secretários de embaixada chegaram a enviados. Uma trajetória que não foi, nem de longe, recorrente. Foram casos excepcionais e que traduzem o bom desempenho deles nos cargos que ocuparam.

Ana Luiza de Castro Pereira Gomes é bolsista Pós-Doc FCT/ MCTES SFRH/BPD/68478/2010

${ }^{31}$ Biblioteca Pública Municipal do Porto, Ms. 480, fl. 96 v. 


\section{Referências bibliográficas}

AMZALAK, Moses Bensabat. As relações diplomáticas entre Portugal e a França no reinado de d. João IV, 1640-1656. Lisboa: [s.n.], 1943.

BLUTEAU, Raphael. Vocabulário português e latino. Coimbra: Collegio das Artes da Companhia de Jesus, 1728a. v. 3.

. Vocabulário português e latino. Coimbra: Collegio das Artes da Companhia de Jesus, 1728b. v. 6 .

. Vocabulário português e latino. Coimbra: Collegio das Artes da Companhia de Jesus,

1728c. v. 7.

BROCHADO, José da Cunha. Auto da vida de Adão pay do genero humano, primeiro monarcha do universo. Lisboa: Offic. de Francisco Borges de Sousa, 1761.

. Memórias de José da Cunha Brochado. Cascais: Pelouro da Cultura, 1996.

CARDIM, Pedro. Diplomacia portuguesa no Antigo Regime; perfil sociológico e trajectórias. In: MONTEIRO, Nuno Gonçalo; CARDIM, Pedro; CUNHA, Mafalda Soares (Org.). Optima pars: elites ibero-americanas do Antigo Regime. Lisboa: Imprensa de Ciências Sociais/Instituto de Ciências Sociais da Universidade de Lisboa, 2005.

. Embaixadores e representantes diplomáticos da coroa portuguesa no século XVII.

Cultura, v. 15, p. 47-86, 2002.

CLUNNY, Isabel. D. Luís da Cunha e a ideia de diplomacia em Portugal. Lisboa: Livros Horizonte, 1999.

. O conde de Tarouca e a diplomacia da época moderna. Lisboa: Livros Horizonte, 2006. CORTESÃO, Jaime. Alexandre de Gusmão e o Tratado de Madri. São Paulo: [s.n.], 1950.

DÓRIA, Antônio Álvaro. José da Cunha Brochado: cartas. Lisboa: Livraria Sá da Costa, 1944.

ELIAS, Norbert. La société de cour. Paris: Calmann-Lévy, 1974.

FARIA, Ana Maria Homem Leal de. Arquitectos da paz: a diplomacia portuguesa de 1640 a 1815. Lisboa: Tribuna, 2008.

. Duarte Ribeiro de Macedo: um diplomata moderno (1618-1680). Lisboa: Biblioteca Diplomática do Ministério dos Negócios Estrangeiros, 2005.

FUBINI, Riccardo. Aux origines de la balance des pouvoirs: le système politique en Italie au XV siècle. In: BELY, Lucien; RICHEFORT, Isabelle. L'Europe des Traités de Westphalie: esprit de la diplomatie de l'esprit. Paris: PUF, 2000.

FURTADO, Júnia. Oráculos da geografia iluminista: dom Luís da Cunha e Jean Baptiste Bourguignon d'Anville na construção da cartografia do Brasil. Belo Horizonte: UFMG, 2012.

LOBO, Francisco. Corte na aldeia. Lisboa: Companhia Nacional, 1890. v. 1.

MATTINGLY, Garret. The first resident embassies: madiaeval Italian origens of modern diplomacy. Speculum, v. 12, p. 423-439, 2003. Disponível em: <http://www.jstor.org/stable/2849298>. MONTEIRO, Nuno Gonçalo. O crepúsculo dos grandes: a casa e o patrimônio da aristocracia em Portugal, 1750-1832. Lisboa: INCM, 2003.

O CASO de Barbiseux. In: BROCHADO, José da Cunha. Memórias de José da Cunha Brochado. Cascais: Pelouro da Cultura, 1996.

SANTARÉM, Visconde de. Quando elementar das relações políticas e diplomáticas de Portugal. Pariz: Aillaud, 1843. v. 4.

SILVA, Abílio Dinis da. D. Luís da Cunha: diplomata e “oráculo" da política (1662-1749). CLIO: Revista do Centro de História da Universidade de Lisboa, nova série, v. 18-19, 2008-2009.

. D. Luís da Cunha e o Tratado de Methuen. Porto: [s.n.], 2003.

SILVA, Antônio Moraes. Dicionário da língua portuguesa. Lisboa: Typographia Lacerda, 1789a. v. 1. . Dicionário da língua portuguesa. Lisboa: Typographia Lacerdina, 1789b. v. 2.

VALLADARES, Rafael. A independência de Portugal: guerra e restauração (1640-1680). Lisboa: A Esfera dos Livros, 2006.

VELHO, B. T. Moraes Leite. Estudo histórico das relações diplomáticas e políticas entre a França e Portugal. Lisboa: Companhia Nacional, 1895-1896.

WICQUEFORT, Abraham de. L'ambassadeur et ses fonctions. Cologne: Chez les Janss; Amsterdã: Waesberge, 1730.

XAVIER, Ângela Barreto; HESPANHA, António Manuel. As redes clientelares. In: MATTOSO, José. História de Portugal: o Antigo Regime, 1620-1807. Lisboa: Estampa, 1993. v. 4, p. 381-393. 